\title{
Psychometric properties of a short version of the Job Anxiety Scale
}

\author{
Bjarne Schmalbach ${ }^{1 *}$, Andreas Kalkbrenner ${ }^{2}$, Markus Bassler ${ }^{3}$, Andreas Hinz $^{4}$ and Katja Petrowski ${ }^{2,5}$
}

\begin{abstract}
Background: Occupational stress and specifically job anxiety are crucial factors in determ hing alth Jutcomes, job satisfaction as well as performance. In order to assess this phenomenon, the Job An xie, rale is one of the instruments available. It consists of 70 items that are clustered in 14 subscales and dimens. The aim of this paper is to create a more efficient, short version of the Job Anxiety Scale, while retain the five dimensions, and to assess its psychometric properties.

Methods: The sample consists of 991 - mostly psychosomatic - patients methods of factor analysis and bivariate correlations to explore and test facto ructure and the nomological net of related constructs.
\end{abstract}

Results: After reducing the item pool via the construction of subsets and te, $/ S$ using ant-colony-optimization, a 15item version of the Job Anxiety Scale evinced very good psychometric properties. We found very good model fit, high internal consistency, and invariance across participar ago d sex. It displayed improved discriminant validity compared to the original scale, and we found the expec batte of convergent correlations.

Conclusions: With this short version of the Job An«ety Scalt Searchers can assess job related worries in a much more economic manner. The questionnaire is par. struggle with extensive assessments.

Keywords: Job anxiety scale, JAS, Job rela fed rety, Screening instrument, Scale construction, Job assessment, (215 words)

\section{Background}

Occupational stressors are cruci explictors in explaing a wide range of positive and legau $e$ job-related outcomes. For instance, hignt evels of job-related stress and anxiety have been sil job satisfaction a id com tment to the job [1, 2]. Motowidlo, Packard, Mannyg [3] even suggest an impact on performance bas on the frequency of stressful experiences. $t$ is estimated that almost $5 \%$ of German employees a ar ris of being absent from work because of

\footnotetext{
orres andence: bjarne.schmalbach@gmail.com

'D 'tmem of Psychosomatic Medicine and Psychotherapy, University

Medic enter of the Johannes Gutenberg University Mainz, Untere

Zahlbac,ner Str. 8, 55131 Mainz, Germany

Full list of author information is available at the end of the article
}

job anxiety [4]. This fact is associated with high costs for companies, health insurance and public pension funds. Thus, research into the phenomenon and a reliable and valid assessment of the construct are of great interest to researchers and practitioners alike.

People who experience job anxiety feel typical anxiety symptoms such as trembling, blushing or palpitations when they are at work or when they think of their work [5]. Even though these symptoms have a major influence on work performance, there is no ICD code for work place phobia. Haines, Williams, and Carson [6] used the criteria of phobia to characterize workplace related anxieties: intense anxiety when approaching the workplace, incapacity to enter the workplace because of anxiety respectively panic symptoms and a reduction of anxiety

$$
\begin{aligned}
& \text { (c) The Author(s). } 2020 \text { Open Access This article is licensed under a Creative Commons Attribution } 4.0 \text { International License, } \\
& \text { which permits use, sharing, adaptation, distribution and reproduction in any medium or format, as long as you give } \\
& \text { appropriate credit to the original author(s) and the source, provide a link to the Creative Commons licence, and indicate if } \\
& \text { changes were made. The images or other third party material in this article are included in the article's Creative Commons } \\
& \text { licence, unless indicated otherwise in a credit line to the material. If material is not included in the article's Creative Commons } \\
& \text { licence and your intended use is not permitted by statutory regulation or exceeds the permitted use, you will need to obtain } \\
& \text { permission directly from the copyright holder. To view a copy of this licence, visit http://creativecommons.org/licenses/by/4.0/. } \\
& \text { The Creative Commons Public Domain Dedication waiver (http://creativecommons.org/publicdomain/zero/1.0/) applies to the } \\
& \text { data made available in this article, unless otherwise stated in a credit line to the data. }
\end{aligned}
$$


when leaving the workplace. Bryson, Barth, and DaleOlsen [7] used parts of Warr's anxiety-contentment axis model [8] for measuring job anxiety. Even though it is a clinically and economically important construct, there is only one questionnaire available for measuring job anxiety - the Job Anxiety Scale (JAS) [9].

Muschalla [10] ran a pilot study, using an initial version of the JAS with 106 items. This version contained criteria of anxiety related to ICD 10 [11], DSM-IV [12] and patient reported aspects of job related anxieties. Based on this first trial, Linden, Muschalla, and Olbrich [9] modified the scale into its current version containing 70 items. The 70 items of the JAS questionnaire are clustered by theoretical assumptions in 14 subscales and five dimensions. The five dimensions assess issues related to stimulus-related anxiety and avoidance behavior, social anxieties and cognition of mobbing, health- and body-related anxieties, cognitions of insufficiency, as well as job-related worrying. An overview of all JAS dimensions and a selection of items can be found in Table 1 . For the assessment of job-related anxiety each subscale and dimension as well as a global mean value can be analyzed based on the 70 JAS items. The psychometric properties of the JAS show very good values for
Cronbach's alpha ( $\alpha=.98$ [9];). The JAS also shows good results for retest-reliability: .85 [9] and .82 [4]. Concerning convergent validity, the correlation with the StaitTrait Anxiety Inventory (STAI-T [13] resulted in .69 [9] and .67 [4]. Job stressors and anxiety have been shown to be associated positively with adverse mental health outcomes $[5,14]$, and negatively with social sur rort and well-being [15-17].

For a more economical way of screening job $\mathrm{h}$ d anxiety there is a Workplace Phobia o (WP [18]). This questionnaire consists of 13 put of 78 items. These items were selected from te JAS - n n empirically driven. The authors took a tems from the subscales Anticipatory anxit ( $\mathrm{t}$, items), Phobic avoidance (six items) ard the items of the Global workplace-anxiety su'ss Since/anticipatory anxieties and avoidance behavior are e central aspects of phobia, the WPS captures $p$ obia ana criteria of clinic disorders.

However, the non-phobia, clinio ecific, comprehensive assessment of job anxie in the manner the JAS does. Specifically, cognitions obbing and insufficiency as well as health-related thought patterns are not captured. We seu to remedy this issue with the present study.

Table 1 Descriptive statistics of the JAS-15 items and scales

\begin{tabular}{|c|c|c|c|c|c|c|c|}
\hline & M & SD & $\gamma 1$ & $\gamma^{2}$ & $r_{i t}$ & $\lambda$ & $\omega$ \\
\hline Stimulus-related anxiety and avoidance behavior & 1.064 & 1.152 & .962 & -.145 & & & .784 \\
\hline Whenever possible, I avoid coming near to the & .940 & 1.368 & 1.221 & .050 & .671 & .800 & \\
\hline After work, I hurry up more than others just to & 1.143 & 1.389 & .947 & -.469 & .638 & .794 & \\
\hline $\begin{array}{l}\text { I have once experienced a terrible event at the vorkplace which is still present in my mind and } \\
\text { makes me feel frightened at work. }\end{array}$ & 1.110 & 1.420 & 1.016 & -.398 & .505 & .627 & \\
\hline Social anxiety and cognition of mobbir & 1.072 & 1.084 & .913 & -.071 & & & .745 \\
\hline At the workplace, I have got problems wirn & .994 & 1.233 & 1.229 & .470 & .540 & .568 & \\
\hline I have got proble & 1.238 & 1.439 & .883 & -.640 & .611 & .688 & \\
\hline L nersons' arbitrary behaviors and unfairness. & .985 & 1.278 & 1.192 & .261 & .628 & .836 & \\
\hline Health- & 1.619 & 1.324 & .440 & -1.084 & & & .921 \\
\hline & 1.572 & 1.408 & .492 & -1.065 & .687 & .924 & \\
\hline his Kaplace, this will cause harm to my health. & 1.548 & 1.463 & .527 & -1.120 & .843 & .889 & \\
\hline causing ill health. & 1.737 & 1.413 & .335 & -1.181 & .796 & .860 & \\
\hline & 1.690 & 1.226 & .315 & -1.054 & & & .825 \\
\hline Under which I work make me nervous. & 1.654 & 1.405 & .382 & -1.148 & .743 & .884 & \\
\hline my capacities for achievement. & 1.828 & 1.406 & .230 & -1.266 & .682 & .735 & \\
\hline I suffer, om the fact that I never know what comes up next at my workplace. & 1.587 & 1.429 & .451 & -1.160 & .667 & .722 & \\
\hline Job-related worrying & 1.653 & 1.225 & .334 & -.991 & & & .854 \\
\hline I am always worrying about minor matters in my work and during all the working day. & 1.734 & 1.365 & .342 & -1.110 & .789 & .910 & \\
\hline Colleagues or family have already told me that I should not always worry that much about work. & 1.491 & 1.399 & .538 & -1.006 & .547 & .594 & \\
\hline I am suffering from the worries which I cannot put away or stop. & 1.735 & 1.470 & .308 & -1.296 & .771 & .907 & \\
\hline JAS Total Score & 1.420 & 1.031 & .538 & -.669 & & & .953 \\
\hline
\end{tabular}

$M=$ Mean; $S D=$ Standard deviation; $\gamma 1=$ skewness; $\gamma 2=$ excess kurtosis; $r_{i t}=$ corrected item-total correlation for the shortened scales; $\lambda=$ standardized factor loading; $\omega=$ reliability coefficient 
Furthermore, as job anxiety is not an ICD diagnoses or clinical diagnoses, there is a need for a scale, which measures work-related worries as a wider construct but in a more economic manner. Especially for big surveys in non-clinical and work-related contexts a shorter version to measure job anxieties needs to be established. Therefore, the aim of this study is to create an empirically derived, economic, short version of the JAS and the assessment of its psychometric properties. To this end, we will reduce the initial 70-item JAS by statistical means while retaining the five theoretically meaningful dimensions. To allow for the construction of an efficient screening instrument, we aim to retain three items per dimension. In addition, we will investigate the shortened scales with regard to their convergent validity by examining its associations with a measure of psychosocial health.

\section{Methods}

\section{Study sample}

We recruited the sample in the Clinic of Psychotherapy and Psychosomatic Medicine, University Hospital Dresden $(n=284)$ and the Rehabilitation Center Oberharz $(n=758)$. We focused on patients and individuals in rehabilitation because, first, the JAS was developed in a similar setting [9], and second, such as sample (vs. a general population sample) will yield a broader distrioution of the characteristic in question.

Description Dresden: Included are $169 \mathrm{femal} \propto \mathrm{C}$ (59. with a mean age of 36.64 $(S D=13.19) \mathrm{y}$ a and $1 \mathrm{l}$ males $(40.5 \%)$ with a mean age of 3734 ( $\left.S_{\perp} \quad 12,20\right)$ years. The overall mean age of the sample was 36.94 $(S D=12.88$; range, 17 to 83 ) years. $5.7 \%$ of the sample lived alone in their household, $71.5 \%$ the ample lived together with one or more peo The diagnoses for this group are displayed in Table 2.
Description Oberharz: The second group $(N=758)$ consists of patients from the "Rehabilitation Center Oberharz" (Rehazentrum Oberharz). Four hundred eleven females $(54.2 \%)$ with a mean age of 46.90 ( $S D=$ 8.66) years and 347 males $(45.8 \%)$ with a mean age of 47.14 $(S D=9.99)$ years were assessed in this sampl The overall mean age of the sample was $47.01 \quad(C)=9.29$; range, 18 to 74 ) years. The diagnoses for this g $p$ are also displayed in Table 2 .

All participants volunteered and rece. $d$ a da'a protection declaration in agreement witit the ${ }^{1}$ sirki Declaration. The study was approver the ethics committee of the Medical Faculty of the : chnische Universität, Dresden (EK 79032011). Vo l a consent was obtained fro $m$ all $p$. icipants.

The JAS questionnz re has aly eady been described in the section "Background." consists of five dimensions, 14 subscales an $/ 4$ tems. Each item was scored on a 5point Likert sca $r \quad$ from of 0 (no agreement) to 4 (full agreement) - th no reverse-scored items. Reliability (Cronbac was veported as being .96 [9].

We used the 1, amburg Modules for the Assessment of Psychosoica Health (HEALTH $[19,20]$ ) to measure genera sychosocial well-being and health in the respondents It uses 49 items to assess nine subscales (and a ch.ological symptoms aggregate), which include among others mental health symptoms, self-efficacy, well-being, as well as social support and participation. As per Rabung et al. [19], internal consistency is acceptable to very good for all subscales with values between $\alpha=.73$ and .91 .

\section{Statistical analyses}

All analyses were performed in $\mathrm{R}$, using the packages lavaan, lordif semTools, and stuart [21-24]. Missing

Table 2 Diagnoses of 10

Diagnoses of the Pati hts from th Technische Universität Dresden, University Hospital Carl Gustav Carus ( $n=277)$ )

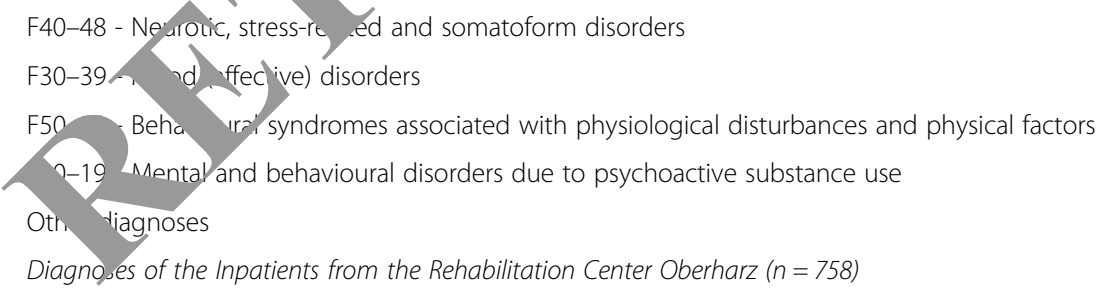

Frequency $\quad \%$

$151 \quad 54.5$

$89-32.1$

$4-1.4$

$3 \quad 1.1$

$30-10.8$

F40-48 - Neurotic, stress-related and somatoform disorders Frequency $\quad \%$

F30-39 - Mood (affective) disorders

M50-54 - Other dorsopathies

F60-69 - Disorders of adult personality and behaviour 
values were replaced by linear interpolation up to a limit of $5 \%$ missing values. Data sets containing more than $5 \%$ missing values were deleted. In accordance with Hair, Black, Babin, and Anderson [25] and Kim [26], we first eliminated those items that evinced unacceptable descriptive statistics with regard to their item-total correlation $\left(r_{i t}<.50\right)$, their skewness $(>|2|)$, and their excess kurtosis $(>|4|)$.

Next, we randomly split the full sample $(n=991)$ into an exploratory $(n=489)$ and a confirmatory subsample $(n=502)$. Using the exploratory sample, we further reduced the remaining item pool of 64 items to 15 items (five scales, three items per scale). Stuart employs antcolony-optimization to construct and test subsets of the given indicators for a given factor structure. Apart from a 5 factor $\times 3$ item structure, we constrained the algorithm to prefer solutions that are strongly invariant across participant sex. We then conducted confirmatory factor analysis using lavaan in the confirmatory subsample, using robust maximum likelihood estimation [27] and robust formulas for the estimation of fit indices [28, 29]. To evaluate model fit, we employed the commonly recommended indicators and cutoffs [30, 31]: $\chi^{2}$-test (non-significant), $x^{2} / d f(<2)$, Comparative Fit Index $(C F I>.95)$, the Tucker-Lewis Index $(T L I>.95)$, the Root Mean Square Error of Approximation $(R M S E A<.08)$, and the Standardized Root Mean Square Residual (SRMR <.00)\% We report reliability as McDonald's $\omega$, which is tI pr ferred measure of internal consistency [32].

For the investigation of measurement in. ince, $w$ used the common step-wise model comparison roach [33]. In this procedure, one compares i icreasingly $r$ s strictive models to establish increasingly s ict level of invariance. Specifically, the first step is the mpa ison of the configural (unconstrained) mor with the metric (equal factor loadings across compared gron on model. Second, one compares the metri- the calar (equal item intercepts across compar oro nc) model. Finally, one compares the scalar to the ict (equal residual terms across compared groy model. $\sigma$ evince measurement invariance, $x^{2}$ should $n$ be significant and the difference in $C F I$ and amma hat $(, H)$ should not exceed .01 [34].

To su le . ent these analyses, we conducted analyses

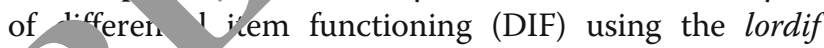
acka e [21) lordif is based in the item response theory fi ewon and utilizes ordinal logistic regression to com $_{1}$ models that account for the effects of (1) ability, (2) ability + group, and (3) ability + group + the ability-X-group interaction. Differences between Models 1 and 2 represent the influence of uniform DIF (which corresponds to group-specific item intercepts in the factor analysis framework), whereas differences between Models 2 and 3 represent the influence of non-uniform DIF across the trait spectrum (which corresponds to differences in factor loadings).

\section{Results}

Descriptive statistics were satisfactory for most of the JAS items. Only six items failed the standards with regard to their item-total correlation $(24,31,70,53)$ and their skewness $(52,56)$ and were removed from consideration. The remaining 64 items were then inpy into stuart for exploratory analysis. Among the $7,6 \times 10^{11}$ possible combinations, the algorithm revealed Dest model fit for the items displayed in Table $1, x^{2}(1)=$ 218.347, $p=.047, \chi^{2} / d f=1.180, \quad C F I=2 . \quad 4, \quad T L 1=.993$, RMSEA $(90 \% C I)=.027(.003 ; .041), 0 R M \Lambda$ 03\%. Next, we tested the discovered model tructure in the independent confirmatory sample wh again revealed very good fit, $X^{2}(80)=171.046, p \quad 001, \quad a f=1.629, C F I=$ .980, TLI $=.974$, RMSFA $(90 \% \quad T I)=.048 \quad(.039 ; .056)$, $S R M R=.036$, affirmirg reduced model. Factor loadings exceeded .50 for all ina tors $(.568 \leq \lambda \leq .924)$, and reliability coefficie its re between $\omega=.745$ and .921 for the five subscales a The shortened JA 15 , total score correlates very highly with the $\quad$ on $r=.973, p<.001$. To further compare the long and st or $\mathrm{to}, \mathrm{ms}$ of the JAS, we generated test information curves ior both versions. As can be seen in Fig. 1, both SCa have similar distributions that can be considered reaconat precise from about $-2 \theta$ to $+2 \theta$. It should be noted, the JAS-15 (vs. the JAS-70) has an information distribucion that is more closely centered around the average trait value of 0 . This means that it assesses more evenly across the trait spectrum, unlike the JAS-70, which has a more pronounced left-skew.

In order to justify the computation of a total score, we also tested a second-order factor model, in which all of the subscales loaded onto a second-order latent variable. This model only decreased marginally in terms of its fit, $X^{2}(85)=257.693, p<.001, X^{2} / d f=3.032, C F I=.977, T L I=$ .971, RMSEA $(90 \% C I)=.053(.046 ; .061), S R M R=.036$. A substantial amount of total variation is explained by the second-order factor, $\omega_{\mathrm{L} 1}=.909$. This result confirms the validity of the total scale score. However, this should not be taken as a sign for the redundancy of the subfactors: A unidimensional model attains unacceptable fit, $\chi^{2}(90)=$ 1026.056, $p<.001, \chi^{2} / d f=11.401, C F I=.868, T L I=.846$, RMSEA $(90 \% C I)=.123(.116 ; .130)$, SRMR $=.055$, despite its very high internal consistency of $\omega=.942$.

We then tested the measurement invariance of the 5factor model across participant sex and age. To avoid statistical dependence with the exploratory analyses, we used only the confirmatory sample when investigating invariance across sex. The results of these analyses are reported in Table 3. There is clear evidence for strict invariance across both sex and age groups. The $x^{2}$-difference test was (marginally) significant for only one of the six model comparisons, and neither $\triangle C F I$ nor $\triangle G H$ exceed .01 between specifications. 
JAS-70
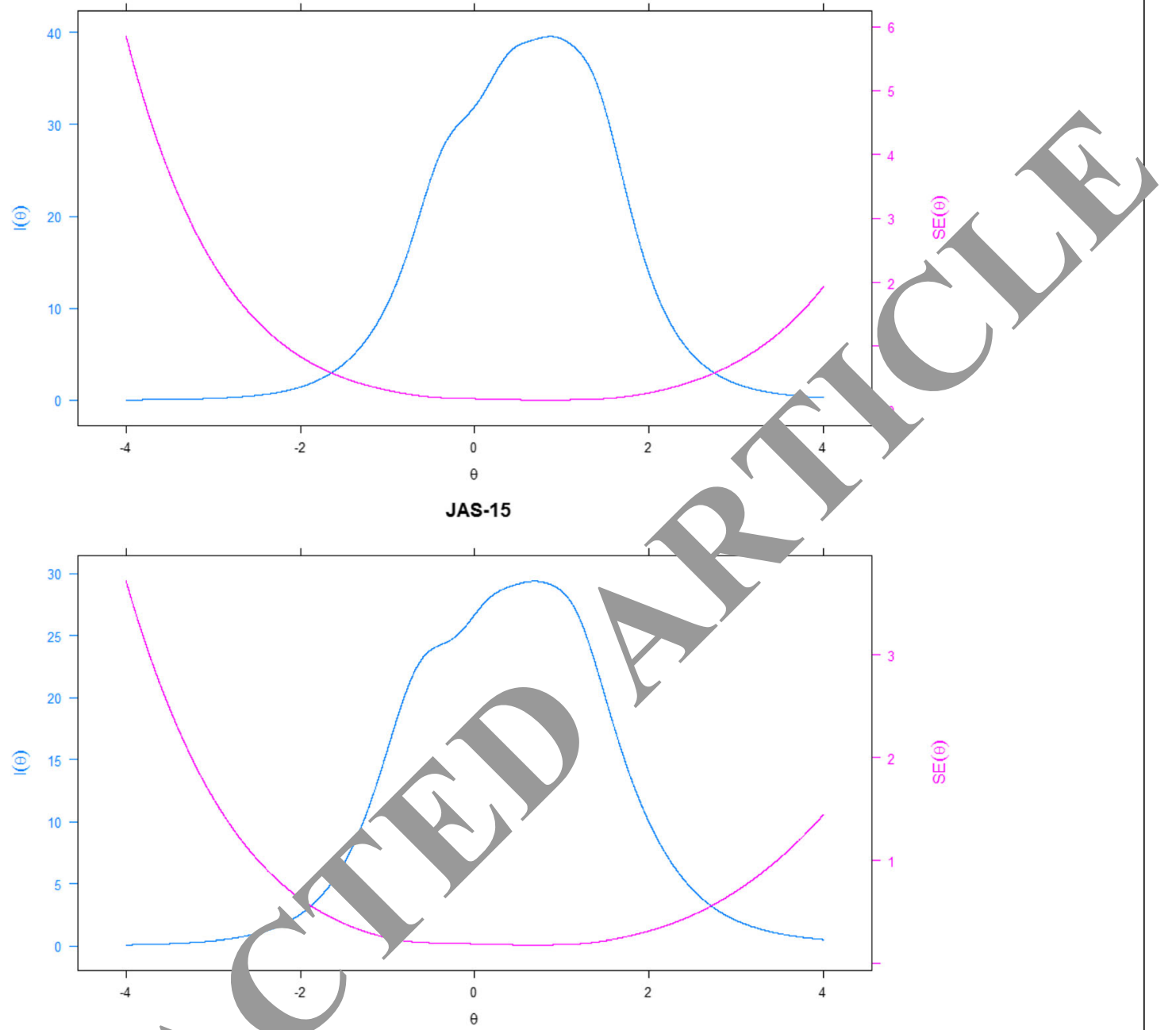

Fig. 1 Test information functions for $\mathrm{and}$ JAS-15. JAS = Job Anxiety Scale

To supplement th f dinos, we conducted itemspecific comparis $\rightarrow$ ins in

In terms of $\mathrm{p}_{a}$ cipant st, we observed a significant $\chi^{2}$ test $(p<.001)$ for $\mathrm{m} 10$ with regard to non-uniform

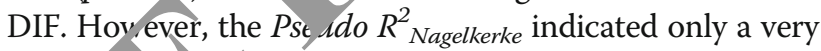
small $e_{L}+$ ze. With regard to participant age, we again fou a vificant $\chi^{2}$ between groups for Item 10 $<$ < 1), bu also for Item $7(p<.001)$. This time the efto munuted uniform DIF, yet the effect sizes were again negh. Hy small: $R_{\text {Nagelkerke }}^{2}=.006$ and .003 , respectively.

Thus, the analysis of DIF and the multigroup confirmatory factor analysis overall yielded the same result: There is no substantial influence of sex or age on the measurement processes of the JAS-15.

Next, we examined the convergent validity of the JAS15 (see Tables 4 and 5). Correlating the short-form with the original 70-item version of the instrument, it became clear that there is strong overlap between the two $(r$ $\sim .90$ and greater), and the original meanings of the JAS70 subscales and the total have been retained. Nonetheless, there were some improvements in terms of its discriminant validity: The mean inter-correlations between its subscales went from $r=.839$ to $r=.666$. Despite the latter still being a highly significant correlation, it is considerably smaller than the mean overlap of the original, $\Delta r=.173, z=14.07, p<.001$. In terms of convergent validity, we found the expected pattern of correlations with the HEALTH-49. Namely, symptoms of mental distress and social restrictions correlated positively with job anxiety, and indicators of well-being and social integration evinced negative associations. To synthesize these results into a more comprehensive format we also ran a canonical correlation analysis. This yielded canonical correlation coefficients $R$ of $.571, .248, .218, .144$, and .093 - with the first three being significant contributors $(p<.001)$. 
Table 3 Fit indices for the analysis of measurement invariance

\begin{tabular}{|c|c|c|c|c|c|c|c|c|}
\hline Model & $x^{2}(d f)$ & $\Delta x^{2}$ & $\Delta d f$ & $\Delta p$ & CFI & $\Delta C F I$ & $\mathrm{GH}$ & $\Delta G H$ \\
\hline \multicolumn{9}{|l|}{ Sex } \\
\hline Female & $156.813(85)$ & & & & .978 & & .978 & \\
\hline Male & $166.236(85)$ & & & & .980 & & .981 & \\
\hline \multicolumn{9}{|l|}{ Multigroup analysis } \\
\hline Configural invariance & $301.099(170)$ & & & & .965 & & .900 & \\
\hline Metric invariance & $325.179(184)$ & 24.081 & 14 & .045 & .963 & .002 & & \\
\hline Scalar invariance & $340.284(193)$ & 15.104 & 9 & .088 & .962 & .001 & & .002 \\
\hline Strict invariance & $348.501(208)$ & 8.218 & 15 & .915 & .963 & & & .002 \\
\hline \multicolumn{9}{|l|}{ Age, years } \\
\hline$\leq 40$ & $140.098(85)$ & & & & .976 & & & \\
\hline $41-50$ & $164.961(85)$ & & & & & & .968 & \\
\hline$\geq 51$ & $131.966(85)$ & & & & & & .982 & \\
\hline \multicolumn{9}{|l|}{ Multigroup analysis } \\
\hline Configural invariance & $437.914(255)$ & & & & & & .976 & \\
\hline Metric invariance & $466.423(283)$ & 28.508 & 28 & .438 & & .000 & .976 & .000 \\
\hline Scalar invariance & $493.446(301)$ & 27.023 & 18 & & & .001 & .975 & .001 \\
\hline Strict invariance & $528.328(331)$ & 34.882 & 30 & .2 & 974 & .001 & .974 & .001 \\
\hline
\end{tabular}

$\mathrm{X}^{2}=$ scaled chi square statistic; $\mathrm{CFI}=$ robust comparative fit index; $\mathrm{GH}=$ scaled gamma hat. For part -ipant sex, the analysis was only conducted in the confirmatory sample to avoid statistical dependence with the exploratory analysis

\section{Discussion}

The present study had two aims. The first on wa develop a new short scale of the JAS. The ond ait was to evaluate the psychometric properties of is new JAS short scale. The initial goal migh - seem supel, fuous at first due to the existence of the Workplace Phobia Scale (WPS [18]). However, this ale ocuses on stimulus related panic symptoms and avoidance behavIor; that are the two typical aspects of phobias diagnoses. Therefore, it is a useful clinical tool to screen for work place phobia. In contrast, the new JAS short scale is an empirically-derived extract of items containing job related anxiety symptoms. It is thus based on a much wider construct - retaining all five dimensions that

Table 4 Correlations with in a betwen the JAS-15 and -70

\begin{tabular}{|c|c|c|c|c|c|c|c|c|c|c|}
\hline & $A^{15}$ & $D^{15}$ & $E^{15}$ & Corr. Total $^{15}$ & $A^{70}$ & $\mathrm{~B}^{70}$ & $C^{70}$ & $D^{70}$ & $\mathrm{E}^{70}$ & Corr. Total ${ }^{70}$ \\
\hline$A^{15}$ & $9 \longdiv { . 7 0 4 }$ & .700 & .629 & .808 & .910 & .813 & .760 & .740 & .677 & .835 \\
\hline$B^{15}$ & .624 & .621 & .526 & .705 & .727 & .887 & .639 & .645 & .606 & .711 \\
\hline$C^{15}$ & - & .803 & .658 & .823 & .812 & .720 & .916 & .791 & .679 & .825 \\
\hline$D^{15}$ & & - & .699 & .847 & .846 & .727 & .873 & .896 & .699 & .875 \\
\hline & & & - & .736 & .739 & .655 & .713 & .731 & .879 & .770 \\
\hline & & & & - & .915 & .834 & .880 & .857 & .767 & - \\
\hline & & & & & - & .852 & .892 & .860 & .758 & .931 \\
\hline$B^{70}$ & & & & & & - & .759 & .782 & .731 & .848 \\
\hline$C^{70}$ & & & & & & & - & .867 & .730 & .894 \\
\hline$D^{70}$ & & & & & & & & - & .772 & .899 \\
\hline$E^{70}$ & & & & & & & & & - & .805 \\
\hline Corr. Total ${ }^{70}$ & & & & & & & & & & - \\
\hline
\end{tabular}

${ }^{15}=$ Scales of the shortened Job Anxiety Scale; ${ }^{70}=$ Scales of the original Job Anxiety Scale; Corr. Total = The corrected scale total, excluding the respective subscale; $\mathrm{A}=$ Stimulus-related anxiety and avoidance behavior; $\mathrm{B}=$ Social anxiety and cognition of mobbing; $\mathrm{C}=\mathrm{Health}-$ and body-related anxieties; $\mathrm{D}=$ Cognition of insufficiency; $\mathrm{E}=$ Job-related worrying; all correlations are significant at $p<.001$ 
Table 5 Correlations between the JAS-15 and the HEALTH-49

\begin{tabular}{|c|c|c|c|c|c|c|}
\hline & A & B & C & D & $\mathrm{E}$ & Total \\
\hline HEALTH Somatoform symptoms & $.236^{* *}$ & $.175^{* *}$ & $.279^{* *}$ & $286^{* *}$ & $.329^{* *}$ & $.304^{* *}$ \\
\hline HEALTH Depressive symptoms & $.420^{* *}$ & $.347^{* *}$ & $.329^{* *}$ & $.386^{* *}$ & $.435^{* *}$ & $.443^{* *}$ \\
\hline HEALTH Phobic/Anxious symptoms & $.434^{* *}$ & $.282^{* *}$ & $.290^{* *}$ & $.347^{* *}$ & $.364^{* *}$ & \\
\hline HEALTH Psychological and somatoform symptoms & $.457^{* *}$ & $.347^{* *}$ & $.382^{* *}$ & $.433^{* *}$ & $.452^{* *}$ & \\
\hline HEALTH Psychological well-being & $-.231^{* *}$ & $-.209^{* *}$ & $-.205^{* *}$ & $-.248^{* *}$ & $-.262^{* *}$ & \\
\hline HEALTH Difficulties in interactions & $.347^{* *}$ & $.360^{* *}$ & $.256^{* *}$ & $.357^{* *}$ & & \\
\hline HEALTH Self-efficacy & $-.353^{* *}$ & $-.268^{* *}$ & $-.286^{* *}$ & $-.345^{* *}$ & & \\
\hline HEALTH Activity and participation & $-.246^{* *}$ & $-.220^{* *}$ & $-.239^{* *}$ & $-.277^{* *}$ & & $-.286^{* *}$ \\
\hline HEALTH Social support & $-.145^{* *}$ & $-.103^{* *}$ & $-.093^{*}$ & $-.087^{*}$ & -.078 & $-.116^{* *}$ \\
\hline HEALTH Social distress & $.247^{* *}$ & $.182^{* *}$ & $.119^{* *}$ & & & $.219^{* *}$ \\
\hline
\end{tabular}

made up the original 70-item JAS. This goal was achieved by using model comparisons based on antcolony optimization. As a result, a JAS short scale consisting of 15 items was created.

The second goal was to evaluate the psychometric properties of this new JAS short scale. In the present study, the JAS (70 items) was found to be highly reliable $(\omega=.98)$. This result accords well with the research -01 ducted by Linden et al. [9] who found very good lu s for Cronbach's alpha $(\alpha=.98)$ as well. The $1 \mathrm{cw}$ s t JAS scale (15 items) also achieves a very goo vel of re liability $(\omega=.95)$. Even though the reliabilisy di from .98 to .95 , it can nevertheless be int rpreted as b-ing a very high value. The level of relia ility usually drops when the number of equally well-fitt item is reduced [35]. Apart from the JAS-15 ing a rellable scale, we also found evidence for its strict su surement invariance across age groups part cipant sex. This means that group means ca e $\mathrm{n}$ miningully compared and inferences can be $d$ awn $n$ these comparisons.

A strength of presen study and the JAS-15, is that we disentangred $\mathrm{t}$. JAS dimensions and thus lowered their average inter-c, srelation substantially. While the average $r$ latic $n$ of $r=.666$ is still high, the subscales are rea dayt as shown in factor analysis. In addition, re re ined y 1 ost of the JAS-15's overall predictive power, as ratmed by a near-1-correlation between the JAS-15 and , $9-70$ totals. Moreover, the JAS-15 and its subscales displayed convergent validity with a measure of psychosocial health in the expected manner. It should be noted that the JAS correlated roughly equally $(r \sim .30$ to .40$)$ with the phobia/anxiety subscale of the instrument and with other measures of psychological distress. This apparent "lack" of differential correlation patterns between the different forms of psychological distress can be explained by the fact that the phobia/anxiety subscale of the HEALTH is focused on cir a symptoms such as agoraphobia and specific ph ias (such as fear of elevators).

\section{Limitations}

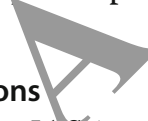
sess $n t$ is tied to the individuals responding to it. mor $g$ other works, Razavi [36] discusses the shortcomin. of these measures - such as acquiescence and social lesirability - as well as potential remedies.

The study is based on data collected in a clinical environment with a large proportion of psychosomatic and rehabilitation patients. Therefore, it appears questionable that the can be transferred without reservation to other clinical and nonclinical populations. Additionally, the sample consisted of 991 patients from two different clinics. A larger sample size from more clinics - or even from the general population - would provide an even wider database.

Only little research has been carried out concerning job-related anxiety. Usually, researchers adapt different instruments or constructs in order to measure job anxiety. Therefore, further research in clinical and nonclinical samples will be necessary in order to understand the underlying construct of job related anxiety. Based on this knowledge, the JAS should be subject to further testing and be further developed. Also, so far it is still unclear how sensitive the JAS might react to changes in a person or an organization. Therefore, the sensitivity of the JAS regarding changes should be tested.

\section{Conclusion}

The aim of this study was to create a new, empirically derived version of the JAS that is both short and efficient and also to assess their psychometric properties. The new JAS short form consists of 15 items, retaining the original five dimensions. Thus, the JAS short form will 


\section{be a helpful instrument in order to screen job related anxiety in an efficient manner.}

\section{Abbreviations}

JAS: Job Anxiety Scale; WPS: Workplace Phobia Scale; CFI: Comparative Fit Index; TLI: Tucker-Lewis Index; RMSEA: Root Mean Square Error of Approximation; SRMR: Standardized Root Mean Square Residual; GH: Gamma Hat; ICD: International Statistical Classification of Diseases and Related Health Problems; DSM: Diagnostic and Statistical Manual of Mental Disorders; STAIT: Stait-Trait-Anxiety Inventory; HEALTH: Hamburg Modules for the Assessment of Psychosoical Health

\section{Acknowledgements}

We acknowledge support by the Open Access Publication Fund of the Johannes Gutenberg University Mainz.

\section{Authors' contributions}

$\mathrm{KP}$ and $\mathrm{MB}$ provided data and supervised the process of creating this paper. AK contributed substantially to conception and design. All authors have made substantial contributions to analysis and interpretation of data. BS and $\mathrm{AH}$ executed the statistical analyses. BS drafted the manuscript and all authors revised it critically for important intellectual content. All authors read and approved the final manuscript.

\section{Funding}

This research received no specific grant from any funding agency in the public, commercial, or not-for-profit sectors.

\section{Availability of data and materials}

All data and materials are available from the corresponding author upon reasonable request.

\section{Ethics approval and consent to participate}

All participants volunteered and received a data protection declarati agreement with the Helsinki Declaration. They gave both, written an informed consent. The study was approved according to the enical guidelines by the Ethical commission of the Medical Faculty Technische Universität Dresden (EK 79032011).

\section{Consent for publication}

Not applicable.

\section{Competing interests}

The authors declare that they have no con interests.

\section{Author details}

'Department of Psychosomat Mea ne and sychotherapy, University Medical Center of the Johann University Mainz, Untere Zahlbacher Str. 8, 55131 Mvainz, o any. 'Technische Universität Dresden, University Hospital C.ustav Caru. Clinic of Psychotherapy and Psychosomatic Me licin tscherstraße 74, 01307 Dresden, Germany. ${ }^{3}$ Hochschule N Mhausen, 99734 Nord ausen, Germany, Department of Medical Psychology and Medical so 'oc Uni ersity of Leipzig, Philipp-Rosenthal-Str. 55, 04103 Leipzia. Gern 5 Uni ersity Medical Center of the Johannes Gutenberg Un, Mainz, dical Psychology and Medical Sociology, Duesbergweg 5513 Mainz, Germany.

\section{Rect d: 24 October 2019 Accepted: 12 April 2020}

Publis aed online: 21 April 2020

\section{References}

1. Borg MG, Riding RJ, Falzon JM. Stress in teaching: a study of occupational stress and its determinants, job satisfaction and career commitment among primary schoolteachers. Educ Psychol. 1991;11(1):59-75.

2. Newbury-Birch D, Kamali F. Psychological stress, anxiety, depression, job satisfaction, and personality characteristics in preregistration house officers. Postgrad Med J. 2001;77(904):109-11.

3. Motowidlo SJ, Packard JS, Manning MR. Occupational stress: its causes and consequences for job performance. J Appl Psychol. 1986;71(4):618.
4. Muschalla B, Heldmann M, Fay D. The significance of job-anxiety in a working population. Occup Med. 2013;63:415-21. https://doi.org/10.1093/ occmed/kqt072.

5. Muschalla B, Linden M, Olbrich D. The relationship between job-anxiety and trait-anxiety - a differential diagnostic investigation with the job-anxietyscale and the state-trait-anxiety-inventory. J Anxiety Disord. 2010;24(3):36671.

6. Haines J, Williams CL, Carson JM. Workplace phobia: psychological and psychophysiological mechanisms. Int J Stress Manag. 2002;9: doi.org/10.1023/A:1015518030340.

7. Bryson A, Barth E, Dale-Olsen H. The effects of organizational chan worker well-being and the moderating role of trade / Gions. ILRRevie 2013:66(4):989-1011.

8. Warr P. Work, happiness, and unhappiness. New Jursey: wah. 2007.

9. Linden M, Muschalla B, Olbrich D. Die job-a gst-Skala (JAS). Fragebogen zur Erfassung arbeitsplatzbezogener Ängst the job anxiety/scale (JAS). A questionnaire for capturing workplace-relat fears]. Zei schrift für Arbeitsund Organisationspsychologie. 20\%0, 26-5

10. Muschalla B. Arbeitsplatzängste und An platzphobie. In: Entwicklung des Fragebogens, Job-Angst-Sk? rur Erfassurn 'eitsplatzbezogener Ängste und seine Erprobung bei patic $\mathrm{n}$ in der psychosomatischen Rehabilitation. Berlin, Deutschlanu e Juniversity Berlin; 2005.

11. World Health Orga nat The ICD, 0 classification of mental and behavioural dis ters: c sical descríptions and diagnostic guidelines. Geneva: World hy uron; 1992.

12. American Psychiatric ociation. Diagnostic and statistical manual of mental ders (DSM) 1. Washington: American Psychiatric Association; 1994.

13. Spielberge CD. Manual for the state-trait anxiety inventory: STAl (form Y). Palo Alto, C1: Consulting Psychologists Press; 1983.

bson J, Beach JR. An investigation of the relationship between hological health and workload among managers. Occup Med. 2000; 50 :518-22.

Ar del-Halim AA. Social support and managerial affective responses to job stress. J Organ Behav. 1982;3(4):281-95.

Greenglass ER. Work stress, coping, and social support: implications for women's occupational well-being. In: Nelson DL, Burke RJ, editors. Gender, work stress and health. Washington: American Psychological Association; 2002. p. 85-96.

17. Warr $P$. The measurement of well-being and other aspects of mental health J Occup Psychol. 1990;63(3):193-210.

18. Muschalla B, Linden M. The job-phobia-scale - a screening instrument in medical rehabilitation. Ärztliche Psychotherapie. 2008;3:258-62.

19. Rabung S, Harfst T, Kawski S, Koch U, Wittchen HU, Schulz H. Psychometrische Überprüfung einer verkürzten version der hamburger module zur Erfassung allgemeiner Aspekte psychosozialer Gesundheit für die therapeutische praxis (HEALTH-49) [psychometric inspection of a shortened version of the Hamburg modules for the assessment of psychosocial HEALTH (HEALTH)]. Z Psychosom Med Psychother. 2009;55(2): 162-79.

20. Rabung S, Harfst T, Koch U, Wittchen HU, Schulz H. Hamburger Module zur Erfassung allgemeiner Aspekte psychosozialer Gesundheit für die therapeutische Praxis (HEALTH)-psychometrische Überprüfung eines neuen Selbstbeurteilungsinstruments zur multidimensionalen Erfassung psychosozialer Gesundheit. Phys Med Rehab Kuror. 2007;17:133-40.

21. Choi SW, Gibbons LE, Crane PK. Lordif: logistic ordinal regression differential item functioning using IRT. R Package Version. 2016;0:3-3 Retrieved from https://CRAN.R-project.org/package=lordif.

22. Jorgensen TD, Pornprasertmanit S, Schoemann AM, Rosseel Y. semTools: useful tools for structural equation modeling. R Package Version. 2018;0:5-1 Retrieved from https://CRAN.R-project.org/package=semTools.

23. Rosseel Y. Lavaan: an $\mathrm{R}$ package for structural equation modeling. J Stat Softw. 2012;48(2):1-36 Retrieved from http://www.jstatsoft.org/v48/i02/.

24. Schultze, M. (2018). Stuart: subtests using algorithmic rummaging techniques. R package version 0.7.3. Retrieved from https://CRAN.R-project. org/package=stuart.

25. Hair JF, Black WC, Babin BJ, Anderson RE. Multivariate Data Analysis. Upper Saddle River: Pearson Prentice Hall; 2010.

26. Kim HY. Statistical notes for clinical researchers: assessing normal distribution (2) using skewness and kurtosis. Restor Dent Endod. 2013; 38(1):52-4. 
27. Satorra A, Bentler PM. A scaled difference chi-square test statistic for moment structure analysis. Psychometrika. 2001;66(4):507-14.

28. Brosseau-Liard PE, Savalei V. Adjusting incremental fit indices for nonnormality. Multivar Behav Res. 2014:49(5):460-70.

29. Brosseau-Liard PE, Savalei V, Li L. An investigation of the sample performance of two nonnormality corrections for RMSEA. Multivar Behav Res. 2012;47(6):904-30.

30. Hu LT, Bentler PM. Cutoff criteria for fit indexes in covariance structure analysis: conventional criteria versus new alternatives. Struct Equ Model Multidiscip J. 1999;6(1):1-55.

31. Schermelleh-Engel $\mathrm{K}$, Moosbrugger $\mathrm{H}$, Müller $\mathrm{H}$. Evaluating the fit of structural equation models: tests of significance and descriptive goodnessof-fit measures. Methods Psychol Res Online. 2003;8(2):23-74.

32. Dunn TJ, Baguley T, Brunsden V. From alpha to omega: a practical solution to the pervasive problem of internal consistency estimation. Br J Psychol. 2014;105(3):399-412.

33. Meredith W. Measurement invariance, factor analysis and factorial invariance. Psychometrika. 1993;58(4):525-43.

34. Milfont TL, Fischer R. Testing measurement invariance across groups: applications in cross-cultural research. Int J Psychol Res. 2010;3(1):111-30

35. Bühner M. Einführung in die Test- und Fragebogenkonstruktion. München: Pearson; 2011

36. Razavi T. Self-report measures: an overview of concerns and limitations of questionnaire use in occupational stress research. [discussion papers in accounting and management sciences]. Southampton: University of Southampton School of management; 2001.

\section{Publisher's Note}

Springer Nature remains neutral with regard to jurisdictional claims in published maps and institutional affiliations.
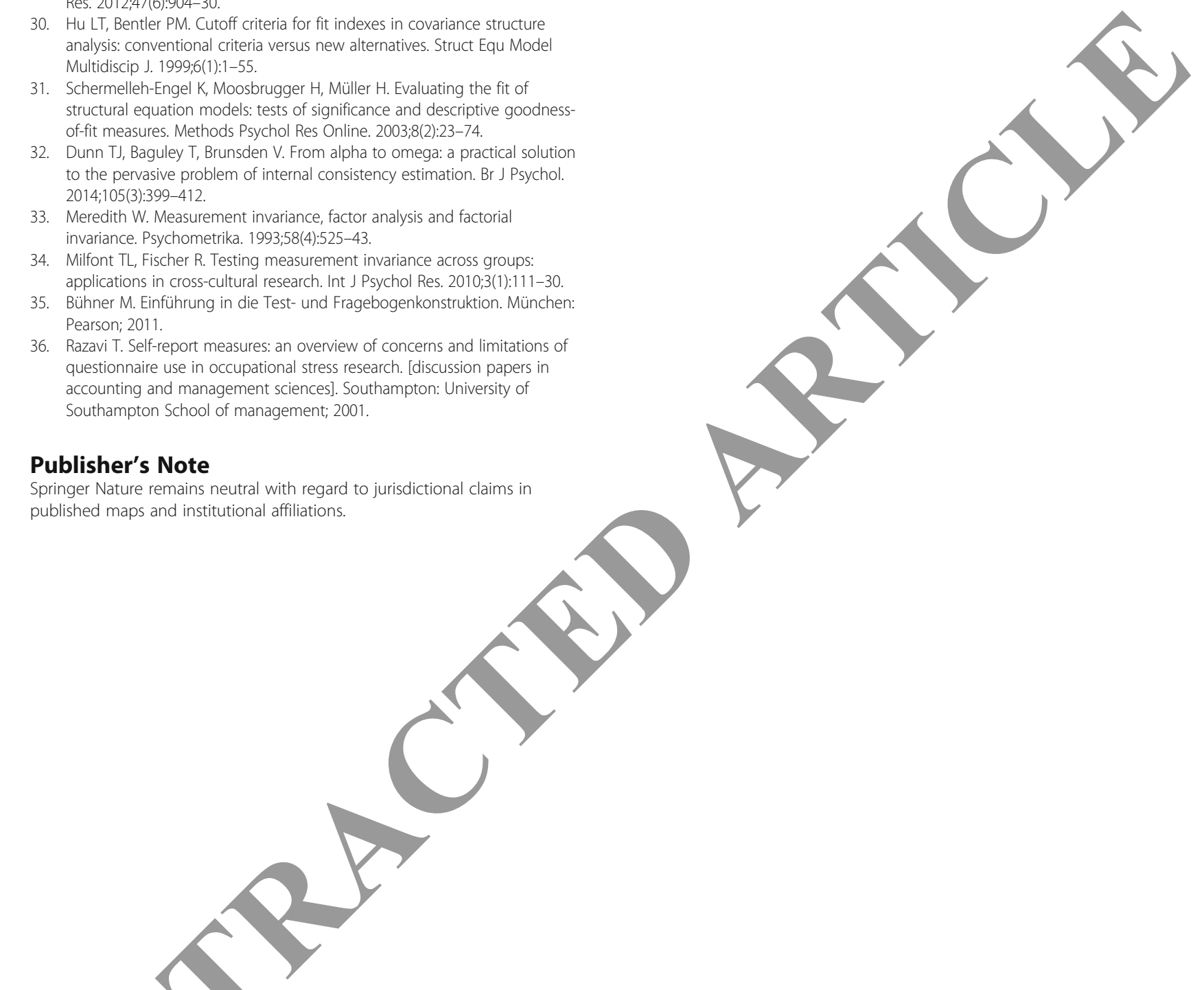

Ready to submit your research? Choose BMC and benefit from:

- fast, convenient online submission

- thorough peer review by experienced researchers in your field

- rapid publication on acceptance

- support for research data, including large and complex data types

- gold Open Access which fosters wider collaboration and increased citations

- maximum visibility for your research: over $100 \mathrm{M}$ website views per year

At $\mathrm{BMC}$, research is always in progress.

Learn more biomedcentral.com/submissions 